\title{
Study on the Modification Mechanism of RPRS Modified Asphalt
}

\author{
Ning $\mathrm{Li}^{1,2, \text { a }}$, Aiqin Shen ${ }^{1}$, Bin Zhou ${ }^{2}$, Wei Huang ${ }^{2}$ \\ ${ }^{1}$ School of Highway, Chang'an University, Xi'an, Shaanxi Province, China. \\ ${ }^{2}$ Yunnan Research Institute of Highway Science and Technology, Kunming, Yunnan Province, China. \\ anbb1010@live.com
}

Keywords: RPRS modified asphalt; modification mechanism.

\begin{abstract}
In this paper, the penetration system and PG classification system were used to analyze the modifying effects of RPRS on asphalt. The basic physical properties of RPRS modifier were showed to analyze the modification mechanism. RPRS showed the feature of plastic hardness during the temperature of $50 \sim 110^{\circ} \mathrm{C}$, and became liquid above $110^{\circ} \mathrm{C}$. Further researches on the modification mechanism were conducted through DSC method, IR spectra analysis and dynamic mechanical analysis. An obvious endothermic process was found when RPRS was at the temperature of $110 \sim 110^{\circ} \mathrm{C}$, indicating the transformation of viscous-elastic state, which was similar to the analysis of basic physical properties. Compared with PEW, a sharp attenuation was found in the transmittance of RPEW, indicating the aging of RPEW. After being mixed with CRM and SBR, the transmittance of RPRS could be recovered.
\end{abstract}

\section{Introduction}

As a kind of asphalt modifier, PE entered the Chinese market early and was relatively well developed at the beginning, but then gradually lost its market competitiveness with the emergence of SBS asphalt modification technology. The main reasons are as following. (1) It needs high speed shearing and other modified methods. (2) The performance of PE modified asphalt at high temperature is not obvious. (3) The segregation problem is not easy to solve. (4) Its shortcomings at low temperature are serious. (5) The cost advantage of PE modified asphalt is not obvious.

In order to solve above problems, the author carried out the research from following aspects: using recycled polyethylene wax (hereinafter referred to as RPEW) to modify asphalt to solve the problem of high temperature performance; producing recovering rubber resin 1 (hereinafter referred to as 3\#PR) through splitting decomposition of RPEW and recycling rubber powder (mass ratio: 85:15) at high temperature (260 degrees centigrade); 3\#PR was mixed with styrene butadiene rubber (SBR) to solve the problem of low temperature performance. Finally, the recycled rubber resin 2 (hereinafter referred to as RPRS) was produced.

Using waste plastics to produce polyethylene wax through thermal decomposition has become an economical and feasible way. At present, polyethylene wax is produced through the pyrolysis of waste polyethylene plastics; solvent-assisted pyrolysis is used to improve the recovery rate of polyethylene wax. [1-3] Polyethylene wax can also be prepared by superheated steam and catalytic cracking. In this paper, recycled polyethylene wax is studied as a basic asphalt modifier. Its production process goes as following. The waste plastic raw materials were heated for seven stages high temperature for 20 minutes $\left(470\right.$ degrees $\left.^{\circ} \mathrm{C}\right)$ to break the molecular chain of polymer and transfer free radical. The reaction still was put into cylinder for cooling and processing. The pulverizer was used to grind and get the final product. The production process of 3 \# PR was as following. RPEW was heated to $220^{\circ} \mathrm{C}$ and added with recycled rubber powder (hereinafter referred to as CRM). After high speed shearing for 1 hour, as well as the cooling and crushing processes, the material of 3 \# PR was obtained. Then RPRS was produced through mixing 3\#PR and SBR at room temperature (mass ratio: 72:38). 


\section{Analysis on the Performances of RPRS Modified Asphalt}

In order to verify the adaptability of RPRS modifier to various kinds of asphalts, popular brands of Maoming (hereinafter referred to as MM), Donghai (hereinafter referred to as DH) and Aisuo (hereinafter referred to as IS) were selected. The RPRS modifier was added to get RPRS modified Maoming asphalt (referred to as RPRS-MM), RPRS modified Donghai asphalt (referred to as RPRS-DH) and RPRS modified Aisuo asphalt (referred to as RPRS-IS).

Table 1 Properties of matrix asphalts and RPRS modified asphalts

\begin{tabular}{|l|l|l|l|l|l|l|l|}
\hline types & $\begin{array}{l}\text { Penetration at } \\
25^{\circ} \mathrm{C} \\
(0.1 \mathrm{~mm})\end{array}$ & $\begin{array}{l}\text { Ductility at } \\
10^{\circ} \mathrm{C}(\mathrm{cm})\end{array}$ & $\begin{array}{l}\text { Softing } \\
\text { Point }\left({ }^{\circ} \mathrm{C}\right)\end{array}$ & $\begin{array}{l}\text { penetration } \\
\text { index }\end{array}$ & $\begin{array}{l}\text { equivalent } \\
\text { softening } \\
\text { point } \mathrm{T}_{800}\end{array}$ & $\begin{array}{l}\text { equivalent } \\
\text { brittle point } \\
\mathrm{T}_{1.2}\end{array}$ & $\begin{array}{l}\text { plasticity } \\
\text { range } \Delta \mathrm{T}\end{array}$ \\
\hline MM & 75.0 & 16 & 56.0 & -0.596 & 50 & -15 & 65 \\
\hline DH & 68.0 & 17 & 54.0 & -0.923 & 49 & -12 & 61 \\
\hline S & 70.0 & 18 & 56.0 & -0.551 & 50 & -14 & 64 \\
\hline SBS & 71.0 & $31\left(5^{\circ} \mathrm{C}\right)$ & 71.0 & -0.066 & 52 & -18 & 70 \\
\hline RPR-MM & 38.7 & $>150$ & 71.5 & -0.551 & 56 & -9 & 65 \\
\hline RPR-DH & 41.1 & $>150$ & 66.5 & -0.506 & 55 & -10 & 65 \\
\hline RPRS-IS & 42.3 & $>150$ & 70.5 & -0.017 & 57 & -13 & 70 \\
\hline
\end{tabular}

As can be seen from table 1, the addition of RPRS reduced the penetration degrees of MM, DH and IS greatly from $70(0.1 \mathrm{~mm})$ to $40(0.1 \mathrm{~mm})$, indicating that RPRS was suitable for the three kinds of asphalts. The decrease of penetration degree meant the decrease of sensitive-temperature properties, and the improvement of temperature performances of asphalts. The ductility of three kinds of matrix asphalt at $10^{\circ} \mathrm{C}$ just met the standard requirements. After adding RPRS, their ductility degrees at 10 degrees centigrade were above $150 \mathrm{~cm}$, indicating that RPRS was suitable for the ductility of three kinds of asphalts. The main reason of ductility increasing was the composition of SBR in RPRS. RPRS addition had relatively great influences on the softening points of $\mathrm{MM}, \mathrm{DH}$ and IS, which increased from about $50^{\circ} \mathrm{C}$ to about $70^{\circ} \mathrm{C}$. The adaptability of RPRS to the softening point of asphalt was relatively good, and was similar to the softening point of SBS. [4]

After adding RPRS, the penetration indexes of three kinds of matrix asphalt increased, indicating that RPRS had better adaptability to the penetration index of asphalt. The penetration index of SBS was the smallest, indicating that its low temperature performance was better.

Table 2 Mixture viscosities and construction temperatures of different asphalts

\begin{tabular}{|l|l|l|l|l|l|l|}
\hline $\begin{array}{l}\text { Sample } \\
\text { number }\end{array}$ & $\begin{array}{l}\text { viscosity } \\
\text { at } 115^{\circ} \mathrm{C} \\
(\mathrm{Pa} \cdot \mathrm{S})\end{array}$ & $\begin{array}{l}\text { viscosity } \\
\text { at } 135^{\circ} \mathrm{C} \\
(\mathrm{Pa} \cdot \mathrm{S})\end{array}$ & $\begin{array}{l}\text { viscosity } \\
\text { at } 155^{\circ} \mathrm{C} \\
(\mathrm{Pa} \cdot \mathrm{S})\end{array}$ & $\begin{array}{l}\text { viscosity } \\
\text { at } 175^{\circ} \mathrm{C} \\
(\mathrm{Pa} \cdot \mathrm{S})\end{array}$ & $\begin{array}{l}\text { mixing } \\
\text { temperature } \\
\left({ }^{\circ} \mathrm{C}\right)\end{array}$ & $\begin{array}{l}\text { compaction } \\
\text { temperature } \\
\left({ }^{\circ} \mathrm{C}\right)\end{array}$ \\
\hline MM & 1.415 & 0.468 & 0.186 & 0.089 & 166.5 & 155.0 \\
\hline DH & 2.535 & 0.485 & 0.195 & 0.093 & 167.0 & 156.0 \\
\hline IS & 1.210 & 0.398 & 0.175 & 0.079 & 163.5 & 150.0 \\
\hline SBS & 4.150 & 1.295 & 0.520 & 0.254 & 178.0 & 174.0 \\
\hline MM3283 & 1.520 & 0.550 & 0.233 & 0.121 & 170.5 & 160.0 \\
\hline DH3283 & 2.460 & 0.725 & 0.279 & 0.132 & 172.5 & 165.0 \\
\hline IS3283 & 1.285 & 0.460 & 0.218 & 0.110 & 168.0 & 155.5 \\
\hline
\end{tabular}

It can be seen from table 2, the Brookfield rotation viscosities of all asphalts decreased with the increasing temperature. The curve of SBS modified asphalt was above all other asphalts, showing that at the same temperature, the viscosity of SBS modified asphalt was higher than that of all other asphalts and the obviously increasing of mixing and compaction temperatures. The viscosities of MM, DH and IS varied slightly from RPRS-MM, RPRS-DH and RPRS-IS, showing that the incorporation of RPRS did not greatly influence the viscosities of modified asphalts. This is of great significance to site construction; on the site, it is not necessary to significantly increase the mixing temperature of asphalt mixture in order to achieve the effect of modification. [5] 


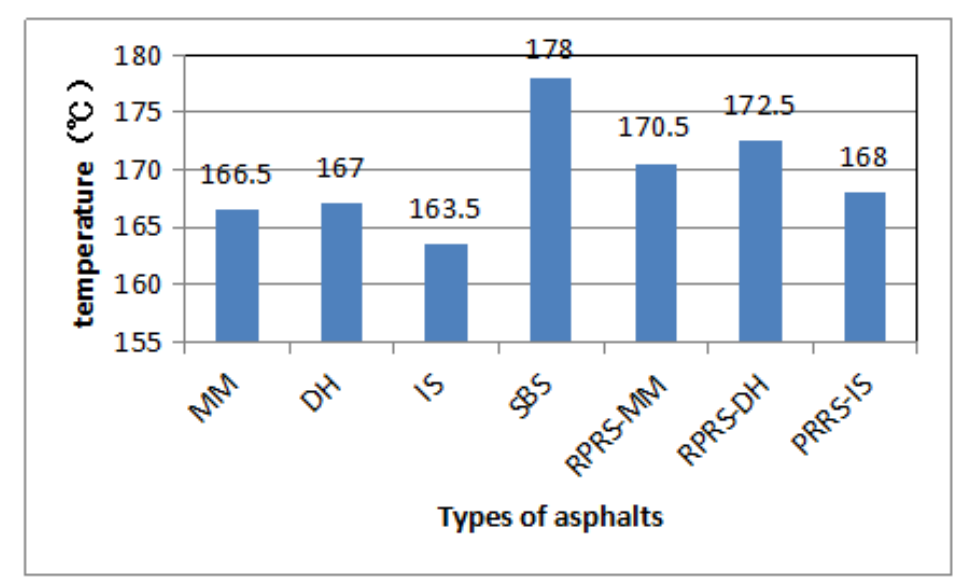

Figure 1 Comparison of mixing temperatures of RPRS modified asphalts

It can be seen from Figure 1, after adding RPRS, the mixing temperatures of three kinds of matrix asphalts increased by 5 degrees. Compared with the mixing temperature of SBS, the temperatures of three kinds of matrix asphalts $\mathrm{MM}, \mathrm{DH}$ and IS increased by $11^{\circ} \mathrm{C}, 11^{\circ} \mathrm{C}$ and $14^{\circ} \mathrm{C}$ respectively. The differences were very obvious. For site construction, the upgrading of material temperature at 5 degrees is relatively easy to achieve; it is not difficult to popularize.

Table 3 Summary of PG grading results of various asphalts

\begin{tabular}{|c|c|c|c|c|c|c|c|}
\hline \multirow[b]{2}{*}{ Type } & \multicolumn{2}{|c|}{ original sample DSR } & \multicolumn{2}{|c|}{ RTFOT residual DSR } & \multicolumn{2}{|c|}{ PAV residual DSR } & \multirow[b]{2}{*}{ PG index } \\
\hline & $\begin{array}{c}\text { test } \\
\text { temperature } \\
\left({ }^{\circ} \mathrm{C}\right) \\
\end{array}$ & $\begin{array}{c}\text { detection } \\
\text { value } \\
(\mathrm{kpa})\end{array}$ & $\begin{array}{c}\text { test } \\
\text { temperature } \\
\left({ }^{\circ} \mathrm{C}\right) \\
\end{array}$ & $\begin{array}{c}\text { detection } \\
\text { value } \\
\text { (kpa) }\end{array}$ & $\begin{array}{c}\text { test } \\
\text { temperature } \\
\left({ }^{\circ} \mathrm{C}\right) \\
\end{array}$ & $\begin{array}{c}\text { detection } \\
\text { value } \\
(\mathrm{kpa})\end{array}$ & \\
\hline MM & 70 & 1.542 & 64 & 3.006 & 28 & 174.4 & PG64-16 \\
\hline $\mathrm{DH}$ & 64 & 1.845 & 64 & 4.009 & 25 & 4075 & PG64-16 \\
\hline IS & 70 & 1.070 & 64 & 2.537 & 28 & 476.6 & PG64-16 \\
\hline SBS & 76 & 1.142 & 70 & 2.832 & 25 & 239.9 & PG70-22 \\
\hline PRRS-MM & 82 & 1.174 & 76 & 3.372 & 34 & 1644.9 & PG76-16 \\
\hline RPRS-DH & 82 & 1.754 & 82 & 3.520 & 37 & 370.8 & PG82-16 \\
\hline RPRS-IS & 88 & 1.154 & 76 & 2.472 & 34 & 248.3 & PG76-16 \\
\hline
\end{tabular}

It can be seen from Table 3 that:

All DSR indexes of matrix asphalts and RPRS could meet technical requirements.

The lowest temperature of RPRS modified asphalts was similar to that of the matrix asphalts; the low temperature performance of RPRS modified asphalt was equivalent to that of matrix asphalt.

The highest temperatures of RSRS modified asphalt were 2 3 grades higher than that of matrix asphalts, and higher than that of SBS modified asphalt for 1 2 grades. The high temperature performance of RSRS modified asphalt was much better than that of matrix asphalts and SBS modified asphalt.

The temperature range of RPRS modified asphalt was equivalent to that of SBS modified asphalt and higher than that of matrix asphalts.

\section{Analysis on Micromechanical Properties of RPRS Modifier}

Netzsch DSC 204F1 Phoenix was used to analyze RPRS modifier through differential scanning calorimetry (hereinafter referred to as DSC). The temperature control program was: $30->200^{\circ} \mathrm{C}$, 
$10^{\circ} \mathrm{C} / \mathrm{min}$; constant temperature 3min; $200->30,-10^{\circ} \mathrm{C} / \mathrm{min}$, constant temperature $3 \mathrm{~min} ; 30->200^{\circ} \mathrm{C}$, $10^{\circ} \mathrm{C} / \mathrm{min}$; constant temperature $3 \mathrm{~min} ; 200->30,-10^{\circ} \mathrm{C} / \mathrm{min}$, constant temperature $3 \mathrm{~min}$. That is to say, the RPRS modifier went through the processes of heating - cooling - heating again- cooling again.

According to the sample curve, the curve of temperature rise at the second time (Figure. 2) was collected to eliminate the thermal history. The peak values of PEW were $36.80^{\circ} \mathrm{C}, 54.32^{\circ} \mathrm{C}$ and $106.86^{\circ} \mathrm{C}$; peak value of RPEW was $99.29^{\circ} \mathrm{C}$; peak value of PR was $99.29^{\circ} \mathrm{C}$; peak value of RPRS was $101.78^{\circ} \mathrm{C}$. The transient transition of RPRS modifier at about $100^{\circ} \mathrm{C}-110^{\circ} \mathrm{C}$ was consistent with the test of softening points.

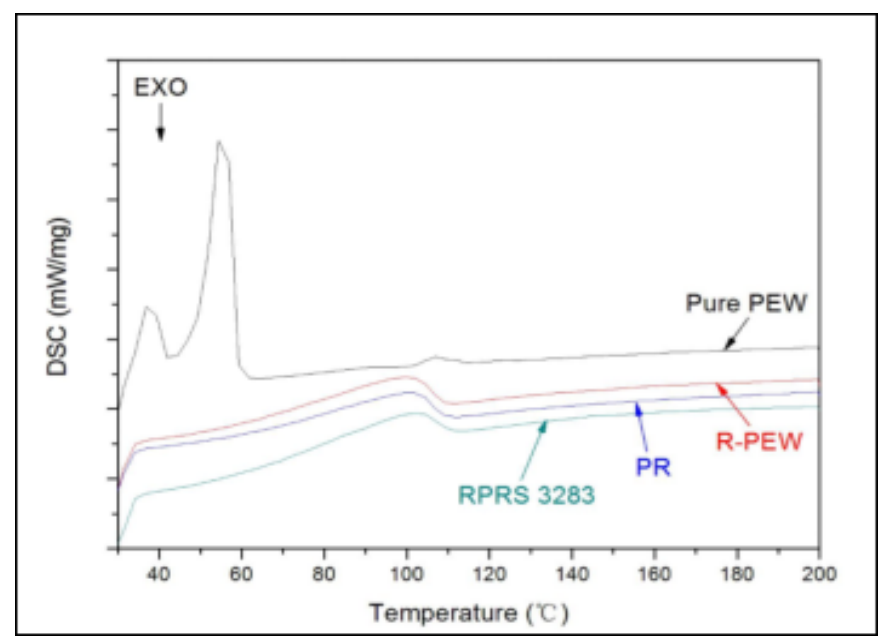

Figure 2. RPRS modifier DSC analysis

The Thermo Scientific Nicolet 6700 was used in the infrared spectrum analysis (hereinafter referred to as the IR) of four modifiers: PEW, RPEW, 3 \# PR and RPRS. [6]

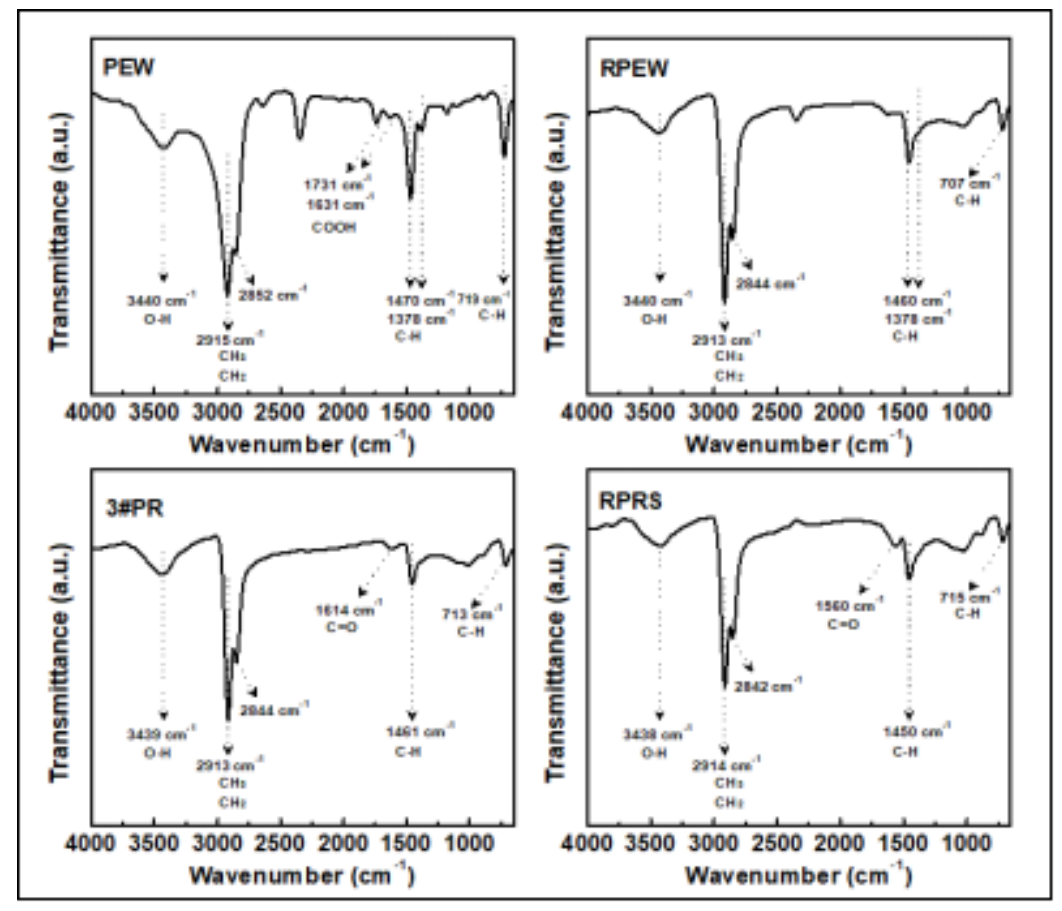

Figure 3. IR analysis of RPRS modifier

From Figure 3, it can be seen that for PEW, the stretching vibration peak of water hydroxyl appeared at $3440 \mathrm{~cm}^{-1}$; the absorption peaks appeared near 2915 and $2852 \mathrm{~cm}^{-1}$ belonged to asymmetric stretching vibration and symmetric stretching vibration of methylene $(\mathrm{CH} 2 / \mathrm{CH} 3)$; the peaks near 1731 and $1631 \mathrm{~cm}^{-1}$ were absorption peaks of carboxyl. ${ }^{[7]}$ The deformation vibration absorption peak of methylene was found at $1470 \mathrm{~cm}^{-1}$; the deformation vibration absorption peak of 
methyl in the branch chain of the structure was found near $1378 \mathrm{~cm}^{-1}$; the absorption peak near $719 \mathrm{~cm}^{-1}$ was a characteristic peak with more than 4 deformation vibrations of methylene. The absorption peaks of the three modifiers of RPEW, 3\#PR and RPRS attenuated compared with PEW at the same location, indicating that the three modifiers had RPEW components and were aging compared with PEW. The absorption peaks of 3\# PR and RPRS also increased compared with RPEW, indicating that the addition of rubber powder and SBR was helpful to improve the performance of RPEW.

\section{Conclusion}

RPRS modifier can significantly improve the high temperature performance of asphalts; the low temperature performance remains at the same level after modification.

DSC test shows an obvious endothermic process of RPRS modifier at $100-110^{\circ} \mathrm{C}$, which leads to great changes in the viscous-elasticity of RPRS modifier.

IR test shows that the absorption peak of RPRS is higher than that of RPEW, indicating that the addition of rubber powder and SBR is helpful to improve the performance of RPEW.

\section{References}

[1] Y. Chang, Study on the technical performance of LDPE and rubber powder composite modified asphalt in stress absorbing layer as mixture, J. Highway Engineering. 4 (2017).

[2] G.T. Gao, Y.T. Zhu, Y. Zhang, et al., Reactive blending behavior of LDPE_SBS blends modified asphalt system, J. China Synthetic Rubber Industry. 5 (2003).

[3] M.P. Li, Y.F. Cong, D. Tang, et al., Development of PE-C9 petroleum resin modified asphalt, J. Contemporary Chemical Industry. 4 (2016).

[4] T. Mei, Y.L. Chi, Y.F. Yi, et al., Study on the properties of polyethylene wax produced by high density polyethylene through pyrolysis, J. China Petroleum Processing Petrochemical Technology. 6 (2011).

[5] X. Wang, X. Ji, S.Y. Li, Progress in the technology of producing polyethylene wax from waste polyethylene plastics, J. Engineering Sciences. 4 (2001).

[6] C.J. He, New technology of making wax from waste polyethylene, CN Patent 1250788A [P]. (2000)

[7] M. Naito, T. Hirata, Process of making wax from waste polyethylene, JA Patent 4959180 [P]. (1972) 